\title{
智能立体车库设计与施工
}

\author{
王博 \\ 中铁十一局集团第六工程有限公司 \\ DOI:10.32629/btr.v2i10.2589
}

[摘 要] 随着我国人均汽车持有量的不断增加, 停车难已经成为困扰大多数群众的生活问题,为了进一步提高空间利用效率, 立体车库的提出则在很大程度上增加了停车位的数量,为群众开车出行创造了良好的条件, 并且很多立体车库中也运用了先进 的智能技术, 智能立体车库成为很多单位及部门首要选用的停车场形式。设计与施工技术作为保障智能立体车库质量的重要 环节,应该得到有效的控制。

[关键词] 智能; 立体; 车库; 设计; 施工

目前, 很多城市都普及了智能立体车库, 其设计施工质量 对于智能立体车库本身质量来说有着重要的意义。所以, 本文 从具体的智能立体车库项目入手进行分析和探讨, 明确了该 项目各个方面的设计要求, 并对其施工过程以及相关准备进 行了介绍, 旨在明确职能立体车库设计与施工的技术要点, 进 一步提升其质量, 保证群众的生命财产安全不受侵害, 同时也 希望能够为今后智能立体车库的优化和改进提供参考。

\section{1 项目概况}

泸州龙马潭区政府智能立体车库位于龙马潭区政府东 南位置, 原位置为篮球场, 东侧为联通大厦, 西侧为龙马潭区 政府会议楼, 现将原篮球场改造为智能立体停车场, 设计使 用寿命不少于 50 年, 该停车场占地面积为 1000 平方米, 建筑 总面积 7900 平方米, 总共 10 层, 地上 9 层其中进出口在地面一 层, 地下一层, 设计总高度 23.80 米, 其中停车层 9 层, SUV3层, 轿车6层, 进出口一层。该车库是全自动智能化停车库, 总计 停车车位 320 。总计设计进出口 8 个, 升降机电梯 4 部, 每小时 连续最大进出车辆150辆。整个车库软件控制将优化停取车 位置, 将靠近巷道的车位全部分配给区政府工作人员, 特点 是存取时间短, 效率快。将剩余的存取时间较慢里排个车位 用于社会车辆办事人员使用。这样既可以是上下班存取车辆 时间较短, 同时又能满足平时办事车辆的存放, 车库的外观 与左右两侧的建筑物相融合, 采用外墙装饰, 美观大方。

\section{2 设计技术要求}

由于智能立体车库本身属于以钢结构为主的建筑, 所以 其材料及标准件要求以及喷涂要求是设计的重点, 这两点要 求也是能够直接影响结构力学性质的因素, 本工程的材料及 标准件要求和喷涂要求具体如下:

\section{1 材料及标准件要求}

本工程采用的高强螺栓为 10.8 级以上 (GB 3632-2008), 采 用的普通螺栓为4.6级或4. 8级普通C级螺栓 (GB 5780-2000) ${ }^{[1]}$ 。 焊接材料:

(1) 手工焊接用焊条: Q235与 Q235钢材焊接用E43型焊 条, Q235与Q345钢材焊接采用E45型焊条, Q345与Q345钢材焊 接采用E50型焊条。
(2) 二氧化碳或惰性气体保护焊自动焊或半自动焊用焊 丝焊剂: Q235钢焊接等。

\section{2 喷涂要求}

钢结构需涂装部位涂装前应对构件进行表面抛丸处理, 除锈等级应达到 (GB/T8923-88) 规定的Sa2. 5 级 ${ }^{[2] 。}$

钢结构构件需涂装部位油漆做法如下:

(1) 底漆一遍, 环氧富锌底漆, 涂层厚度 $60 \mu \mathrm{m} 。$

(2) 中间漆二遍, 环氧云铁中间漆, 涂层厚度 $60 \mu \mathrm{m}$ 。

(3) 面漆二遍, 氯化橡胶面漆, 涂层厚度 $40 \mu \mathrm{m}$ 。

（4）外露钢结构和检修困难的部位, 涂层厚度增加 $30 \mu \mathrm{m}$ 。

或者采用静电粉末喷涂后采用高温烘烤或采用镀锌处 理的多种的综合处理 ${ }^{[3]}$ 。

\section{3 施工质量控制措施}

3. 1 制度管理措施

质量控制的对象是过程, 包括采购过程、生产过程等; 为 了使控制的对象达到规定的要求, 工程中将采取科学的质量 管理方法, 健全全面有效的质量管理制度, 建立一整套质量管 理模式, 配以规范化、标准化、科学化和程序化的管理方法。

工程质量奖罚制度: 认真贯彻质量方针, 执行质量标准, 坚决执行项目有关质量管理的奖罚规定, 以技术文件的规定 及现行国家施工验收规范, 质量评定为依据进行奖罚。

在施工现场加大质量考核力度。结合市场经济的实际将 职工的收入、荣誉与本人的工作质量结合起来, 认真落实以 总工程师为核心的质量责任制。

工程质量例会制度: 在整个施工过程中项目部建立每周 一次的质量例会制度, 质量部主持召开, $\mathrm{QC}$ 小组成员及施工 班组质检人员参加。对本周内存在的质量问题一一列举出来, 在会上定出解决方案、责任人、解决期限, 同时对上次例会 中提出问题检查落实解决情况。

不合格项制度: 对现场屡次出现的质量不合格项, 用《质 量整改通知书》的形式下发施工班组, 限期整改, 否则将采取 一定的经济手段。

3. 2 施工过程质量控制措施

在施工中严格执行自检、互检、交接检的 “三检” 制度, 
把好质量关, 严禁不合格工序转入下道工序。

根据工程特点和技术规范的要求, 在施工过程中设立相 应的质量控制, 关键过程和特殊过程制定专门的工艺指导书 指导施工。

加强现场的原材料管理, 加强对物资分供方的控制, 确 保不合格材料不进入现场。

3. 3 钢结构工程成品保护措施

（1）钢构件的堆放

待包装或待运的钢构件, 按种类、安装区域及发货顺序, 分区整齐存放, 标有识别标志, 便于清点。

露天堆放的钢构件, 搁置在干燥无积水处, 防止锈蚀; 底 层垫枕有足够的支承面，防止支点下沉；构件堆放平稳垫实。

相同钢构件的叠放时, 各层钢构件的支点应在同一垂直 线上, 防止钢构件被压坏或变形 ${ }^{[4]}$ 。

钢构件的存储、进出库, 严格按企业制度执行。

（2）钢构件的包装

钢构件的包装和固定的材料要牢固, 以确保在搬运过程 中构件不散失, 不遗落。

构件包装时, 应保证构件不变形, 不损坏, 对于长短不一 容易掉落的对象, 特别注意端头加封包装。

管材型钢构件, 用钢带裸形捆扎打包, $5 \mathrm{~m}$ 以下长捆扎二 圈, $5 \mathrm{~m}$ 以上长捆扎三圈。

机加工零件及小型板件, 装在钢箱或木箱中发运。

包装件必须书写编号、标记、外形尺寸, 如长、宽、高、 全重, 做到标志齐全、清晰 ${ }^{[5]}$ 。

(3) 运输过程中成品保护措施

吊运大件必须有专人负责, 使用合适的工夹具, 严格遵守 吊运规则, 以防止在吊运过程中发生震动、撞击、变形、坠落 或其它损坏。

装载时, 必须有专人监管, 清点上车的箱号及打包号, 车 上堆放牢固稳妥, 并增加必要捆扎, 防止构件松动遗失。

在运输过程中, 保持平稳, 采用车辆装运时对超长、超 宽、超高物件运输, 必须由经过培训的驾驶员, 押运人员负责, 并在车辆上设置标记。

严禁野蛮装卸, 装卸人员装卸前, 要熟悉构件的重量、外 形尺寸, 并检查吊马、索具的情况, 防止意外。

构件到达施工现场后, 及时组织卸货, 分区堆放好。 现场采用履带吊运送构件时, 要注意周围地形、空中情 况, 防止履带吊倾覆及构件碰撞。

(4) 安装成品保护

一方面构件倒运过程中, 要进行钢结构件的保护; 另一
方面还需要进行构件表面防腐底漆及中间漆的保护。

构件保护:

(1)构件进场应堆放整齐, 防止变形和损坏, 堆放时应放 在稳定的枕木上, 并根据构件的编号和安装顺序来分类。

(2)构件堆场应作好排水, 防止积水对钢结构构件的腐蚀。

(3)在拼装、安装作业时, 应尽量避免碰撞、重击。

(4)避免现场焊接过多的辅助构件, 以免对母材造成影响。

(5)在拼装时, 在地面铺设刚性平台, 搭设刚性胎架进行 拼装, 拼装支撑点的设置, 要进行计算, 以免造成构件的永久 变形。

(6)进行桁架的吊装验算, 避免吊点设计不当, 造成构件 的永久变形。

涂装面的保护:

因型钢柱为混凝土内钢柱, 钢柱除锈在混凝土现场浇筑 前实施。

(1)避免尖锐的物体碰撞、摩擦。

(2)减少现场辅助措施的焊接量, 能够采用捆绑、抱䇽的 尽量采用。

\section{4 结束语}

本文主要介绍了沾州龙马潭区政府智能立体车库主要 的设计要点, 以及工程质量控制措施, 这些技术措施都能起 到有效的工程质量控制作用, 并且在实际应用过程中取得了 良好的效果, 是值得推广的智能立体车库质量控制技术。所 以, 在未来智能立体车库质量控制过程中, 我们需要从本文 所阐述的几点入手, 进而建设有质量保证的车库项目。同时, 在施工过程中, 技术人员也要对现有施工技术进行深入的剖 析, 并明确具体的技术问题, 同时采取有效的控制手段, 这样 才能真正促进智能立体车库设计施工技术的提升, 促进智能 立体车库行业的发展。

\section{[参考文献]}

[1]高静.医院智能立体停车库的设计探索与实践 [J].智 能建筑与智慧城市,2018,(10):29-30+68.

[2]谢友春.机械式智能立体车库的创新设计分析[J]. 科 技创新与应用,2018,(25):48-49.

[3]何慧妍.X立体车库公司华南地区竞争战略研究[D].华 南理工大学,2018.

[4]胡义华, 张树林, 靳龙. 回转式小型智能立体车库的结 构设计与研究 [J]. 新型工业化,2018,8(05):66-69.

[5]王新,李春雷.智能立体车库存取车模式研究分析 [J]. 机械工程与自动化,2017,(03):31-32+35. 